\title{
Ensuring Social Impact at Every Stage of Technology Research \& Development
}

\author{
Jeremy Pesner
}

Carnegie Mellon University, Department of Engineering and Public Policy, Pittsburgh, Pennsylvania https://doi.org/10.38126/ISPG180305

Corresponding author: jpesner@andrew.cmu.edu

Keywords: broader impacts; collective impact; commercialization; development; equity; impact assessment; multistakeholder; participatory technology assessment; responsible research; social impact; technology; technology transfer

Executive Summary: Although the United States national innovation system has produced many technologies, their benefits are not evenly distributed across the country's population. This stands in direct contrast to the aims of government, which frequently funds science research for the purpose of social benefit. This paper first undertakes a deep reconsideration of the US national innovation system, and then reframes it as a collective impact initiative in order to coordinate every one of its contributors around this goal. It begins by tracing the origins of the longstanding tensions between science undertaken for the sakes of science inquiry versus societal benefit. It then discusses the inadequacies of practices meant to bridge science outcomes and societal needs like the broader impacts and technology transfer. It concludes by proposing a significant expansion of the stakeholders that evaluate the proposals and outcomes of federally funded research. This integrates diverse public participation into the proposal selection process, research discussions, and technology transfer to ensure that universal social impact is routinely considered.

The benefits of science and technology remain unevenly distributed across racial, gender, economic, and geographic lines. How can we ensure that Americans of all backgrounds are drawn into both the creation and the rewards of science and technology? How can we ensure that science and technology hubs flourish in every part of the country, driving economic development in every American hometown?

- President Biden's letter to incoming Office of Science and Technology Policy director Eric Lander (January 20, 2021)

Scientists alone can establish the objectives of their research, but society, in extending support to science, must take account of its own needs.

- President Kennedy's address to the National Academy of Sciences (October 22, 1963)

\section{Introduction}

Perhaps the most significant motivation to create new technologies is the benefit they can bring to all individuals of society. Vaccines, automobiles, synthetic polymers and the Internet have all immeasurably improved the lives of most people around the world. However, when policymakers discuss the United States (US) science and technology (S\&T) innovation system, we often hear about economic growth, jobs and global competitiveness. The welfare of the most vulnerable and underserved-a key component of social impact-is usually not addressed. Furthermore, S\&T can maintain or even widen the vast societal inequalities we see today (Bozeman 2020; Schillo and Robinson 2017). S\&T often only improves the lives of those in need by happenstance, rather than by deliberate purpose. This points to a major ethical failure among relevant stakeholders in their duties as public servants and recipients of public funding. The US legislative branch is considering a new bill that will empower the National Science Foundation 
(NSF) to address this. The version passed by the Senate specifies a modest increase to NSF's budget, a new "societal challenges" directorate, and a small amount going to certain research fields. The House's version aims to fund a broader array of research fields and is less explicitly focused on competition with China (Ambrose 2021; Lopez 2021; McKinnon 2021). However, neither bill addresses exactly how this increased funding will lead to better social outcomes, particularly for the most vulnerable. This population has few opportunities to help direct our S\&T innovation system. Legislators, science researchers and administrators are often far removed from these stakeholders, and therefore illequipped to represent their needs. We must improve our S\&T system so that all relevant stakeholders both directly contribute to and benefit from its advancements, but first we must understand why they currently do not.

\section{Science for scientists}

The US's modern science policy began with Vannevar Bush (1945). Bush helped to create the National Science Foundation but opposed sponsoring programs that addressed the US's social and economic needs (Kevles 1977). He emphasized the importance of "basic research," which seeks fundamental truths and not applied results. Bush painted the picture of a linear model in which results from basic research are developed into applied technologies. The key example of nuclear physics leading to the atomic bomb spurred confidence that such technologies would lead the US to a prosperous future. This assertion of the potency of basic research satisfied the demands of both scientists and policymakers (Pielke 2010).

Bush and other politically conservative scientists also used this argument to shield science from government control, while those on the progressive left believed that science should be subject to open access and input (Wang 1995). Bush's views were neatly encapsulated in his statement that the US needed a scientist-run government agency dedicated to basic research. Politicians should never manage or instruct scientists in what basic research they should pursue. Bush framed scientific progress as resulting from "the free play of free intellects, working on subjects of their own choice, in the manner dictated by their curiosity for exploration of the unknown" (Sarewitz 2016).
Although Bush popularized this ideal, it did not originate with him. In the 1870 s, scientists fought for a purity of science that prioritized the seeking of truth, denigrating research that applied what others had discovered (Pielke and Byerly 1998). However, this perspective does not adequately serve the society in which science is situated. The US's technological growth of the past half-century has been in spite, rather than because, of a linear model, basic research and the 'free play of free intellects.'

NSF, although not the agency Bush had envisioned, was created in 1950 with several of his philosophies in mind. Its board largely consisted of scientists who were trained with an academic mindset and committed to supporting the best science (Mazuzan 1994). But the "best" science initially only meant "basic science." Support for applied or social science research was not permitted until 1968, with the passage of the Daddario-Kennedy Amendment (Mazuzan 1994; Wilson 1983). Soon afterwards, NSF started a small initiative to connect physical and social sciences. However, following pressure from the Nixon administration turned it into the larger Research Applied to National Needs (RANN) program (Green and Lepkowski 2006). RANN was designed to fund research connected to industrial enterprises around societal concerns like transportation and energy. However, it only lasted a few years; NSF stakeholders grew concerned that social science and applied research would either drain or water down funding for basic science research. This demonstrated that a targeted, impactful program could not find a home at NSF (Bozeman and Boardman 2009; Mazuzan 1994).

Some elements of RANN remain today in the form of funding applied engineering research. However, "gone was the conscious, directed attempt by NSF to seek out specific societal problems" (Green and Lepkowski 2006). While most of its funding today focuses on basic research, NSF still plays a key funding role. It is the only US federal agency "whose mission includes support for all fields of fundamental science and engineering" as well as many of the social sciences (National Science Foundation n.d.). Thus, this paper focuses on NSF, although much discussed here applies to other funding agencies as well. 
Stokes (1997) contested much of the Bush and subsequent NSF philosophy. He demonstrated that many technological innovations have not been the direct result of basic research, but instead of clear societal needs. The goal-oriented research funded by offices like the Defense Advanced Research Projects Agency (DARPA) led to many advancements in military technology. Many of these technologies, like global positioning systems, improved jet engines and computer networking, benefited the civilian sector as well. The applied research that put a man on the moon has since resulted in over 2000 civilian products (National Aeronautics and Space Administration n.d.). Sarewitz (2016) outlines how many of the Industrial Revolution's technological advancements actually opened up new fields of basic science inquiry. Technologies like the steam engine and telegraph both had tremendous social impact and catalyzed related fundamental scientific enterprises. Today, there is widespread agreement that new technologies are not driven solely by advances in basic research, but also by the needs of every person in society. We can define "social impact" as the extent to which S\&T advancements meet these societal needs.

\section{More impact is possible}

Unfortunately, our current S\&T system does not achieve this impact nearly as well as it could. Several of its components have not moved beyond the assumptions of Bush's linear model, keeping them divorced from societal concerns. Many early career researchers are motivated by social impact, but become disillusioned by research that overemphasizes scientific novelty and citation counts (Leeming 2018). However, this disregard of impact conflicts with the goals of government, as "There has never been any doubt in the minds of policy-makers that the ultimate aim for funding science and technology was socioeconomic goals such as national security, economic development, welfare and the environment" (Godin and Doré 2005).

NSF's response to this has been its "broader impacts" (BIs) initiative. BIs were designed to ensure that all NSF-funded research had relevance beyond the academy. However, despite NSF's efforts and intentions, BIs are insufficient to ensure impact. They have frequently been criticized as vague and frustrating for scientists to interpret (Lok 2010). As such, they lack widespread buy-in from the research community. NSF's own reports indicate that many researchers consider the requirements to be an "add-on" (National Science Foundation 2015). Some even seek boilerplate language to check the box, demonstrating that they have no plan or budget to support BIs at all (MacFadden 2019). Additionally, while NSF specifies and requires BIs, it is academic reviewers who actually evaluate them. While researchers are used to judging a proposal's intellectual and scientific merits, they are often not trained, willing or able to evaluate its social impacts (Bozeman and Boardman 2009; Holbrook and Frodeman 2011). Sarewitz (2011) criticizes this arrangement as essentially offloading science's social responsibility onto individual scientists. As a US government agency, NSF should be explicitly coordinating it.

New advances in S\&T can help us solve many of our societal challenges. However, our current research and development (R\&D) ecosystem is disjointed and haphazard. It includes many different stakeholders with many different goals and incentives. They are not collectively optimized for the social impact of science (Prabhakar 2020). In fact, they may be an expression of an outmoded approach to S\&T (Sarewitz 2021). To address this issue, we need a comprehensive, collective impact approach. Academics, funding agencies, businesses, technology transfer offices (TTOs) and all other stakeholders must work together towards the same set of specific goals. This system needs a common agenda, shared measurements, mutually reinforcing activities, continuous communication among stakeholders and dedicated coordinating organizations (Kania and Kramer 2011). This will lay the groundwork for reliable, long-term social change.

Such a system is not currently employed in any systematic fashion. Moreover, the systems that exist have significant limitations. For instance, the National Institutes of Health (NIH) and Department of Defense (DoD) fund particular types of research that are very much expected to result in targeted impacts. However, not all research directly contributes to the interests of those organizations, and DoD cuts funding to some projects that it does not foresee will help those interests (Sarewitz 2016). The tight focus of these agencies often drives impact from the top down: they specify the problem to be 
solved and call for research proposals to solve it. This leaves no room for exploratory impact-driven research developed from the bottom up by researchers themselves. Such research can help to define and discover entirely new fields and avenues of impact. Furthermore, most basic research will not have a direct impact on technological development. Instead, it will have an indirect impact through the creation of new ideas, fundamental understanding or methods for applied research. To accommodate its wide diversity, we need a system for driving impact from research that is agnostic to its funding source, field of science or social science and basic or applied nature.

\section{A new structure for impact}

We must start with the right metrics. Research impacts are distinct from research outputs. Outputs are the direct results of scientific research, while impacts are the long-term effects on society (Godin and Doré 2005). Because they are easily measurable, outputs often serve as barometers for successful research, but do not actually measure its impact. Research cited in patents is often used as evidence of innovation, but "most innovations are not patented, and most patents are not valuable" (Smith and Funk 2021). Technologies like the computer mouse and Universal Serial Bus standard are not patented, while many patents exist for technologies that are not innovative or do not even currently exist. Other output metrics, like number of citations (Ioannidis et al. 2014) or amount of venture funding raised (Alakent et al. 2020), do not correlate with social impact either. While such metrics may help the careers of the individuals involved, we cannot use them to determine the scientific and social welfare of society.

Measuring impact, and who is impacted, is considerably more difficult. There is no clear and universal way to define it. The United Kingdom's National Environmental Research Council has stated that "The economic and societal benefits of science investment are notoriously challenging to evaluate and quantify. It is often easier to demonstrate the process of generating impact, and the kinds of impact we achieve, than to measure the impact itself" (Langfeldt and Scordato 2015). Social impacts differ considerably across different stakeholders and communities. What's more, any impact assessments require human judgment, which are naturally affected by individual biases, perspectives and experiences. Ultimately, the question is not what impact is defined to be or even how it is assessed, but who is assessing it.

Representatives from the full range of affected stakeholders should help evaluate research impact. This is the best way to ensure that impact is considered across the entire $R \& D$ process. While others can attempt to anticipate or guess, only these group representatives can fully assess how they and their peers will be affected (Weller et al. 2020). Alongside low-income and underserved populations, these participants may include VC investors, journalists, startup founders, local governments, manufacturers, students, lawyers, artists, or potential customers, depending on the research. All of them play a role in bringing new technologies to the world. They will learn the S\&T, so they can better anticipate how new developments may lead to changes in their lives. This is similar to advice currently given to researchers about BIs: speak with different types of people to understand what they value in science (Dance 2013). Only now, such individuals will not just advise about potential BIs, but judge them.

These stakeholders will not assess the scientific merit of the proposal-the academic reviewers will still do this. But having different evaluators for the science and impact criteria ensures that each set is evaluated by those most qualified and trained to do so. This could easily lead to a revival and extension of the RANN model (Green and Lepkowski 2006): academics, funding agencies, industry, and those in need all collaborate on research that strives for impact. This will further enable researchers to combine basic and applied research-what Shneiderman (2013) calls an "ecological model" -in service of both academic inquiry and societal impact. Neither need come at the expense of the other.

Certain aspects of this new system are more conducive to applied research, but basic research benefits as well. Even if the potential impact is not obvious or immediate, working with these other stakeholders helps scientists to explain the value of their work. This is especially useful when justifying their funding to politicians like Lamar Smith, who publicly questioned the value of several seemingly pointless research projects (Trager 2015). Any 
research proposal, whether basic or applied, should clearly communicate its value. However, many researchers are not capable of this, as they do not learn to write for the general public (Heleta 2017). The most fundamental research can be impactful (Dance 2013), but it must be framed comprehensibly for its impact to be demonstrable.

However, funding is only the first step, and any researcher can attest to how research evolves from its proposal to its finished form. To track this, relevant stakeholders (whether the same or different ones from before) should also check in during the research process itself. This will allow them to continually discuss its direction, potential impacts and implications. The stakeholders would not evaluate the research quality or have any say in funding. They would simply remain informed. This ensures that academics can clearly describe their work, maintain a shared sense of potential and expectations with outside stakeholders, and develop results that are meaningful to all parties (Schikowitz 2020). These check-ins should not be too formal or structured. Such impositions would only lead to researchers simply checking the box, as some do with BIs. However, meetings where curious stakeholders come to learn about research that might interest or affect them would be much more welcomed; researchers generally enjoy discussing their work. Scientists routinely presenting to the public will never remain too insular. Nor will they ever struggle to fulfill BI requirements again.

Public engagement should not stop once the research is completed. As a bridge between academia and industry, TTOs have significant potential to contribute to research impact. However, they were designed to create economic value from the patents generated from university research (Stevens 2004). None of their regulations specify any kind of social impact (Van Norman and Eisenkot 2017). Therefore, their collective impact mission must expand to explicitly account for impact. The group of outside stakeholders should also routinely advise TTOs on achieving impact.

TTOs should proactively undertake research commercialization and impact efforts even if the researcher is not involved. TTOs can even scout for avenues to do this before the research is completed. They are usually well-networked locally, and often interact with industry in contexts like research parks (McCarthy et al. 2018). However, they can also network nationally or even globally. With no geographic bounds, the best licensees for the research may be a startup, a large corporation, an activist group, a team of students, a hacker/makerspace, an incubator, or an artist collective. Furthermore, the "technology" may not be a drug or device, but a policy, social practice, or educational initiative. Anyone who can help realize that impact must have the opportunity to do so. However, TTOs are often underfunded and lacking in personnel (Loise and Stevens 2010). They will likely need additional financial and personnel support to unlock the full potential impact of their research portfolios.

\section{Placing impact in context}

Many researchers push back on what they call the "impact agenda," claiming that considering social impact limits academic freedom (Holbrook 2017; Nightingale and Scott 2007). If one considers topdown criteria from agencies like NIH and DoD, this makes sense. Researchers generally do not like being told what to work on. They can require a substantial amount of funding to switch to a research topic preferred by a funding agency (Myers 2020). Researchers' specializations, preferences and ambitions should all be taken into account in this process. This is best achieved if they negotiate with the funding agencies to determine how both parties can benefit.

However, the general framing of academic freedom and social impact as a zero-sum game is misplaced. The practice of Responsible Research and Innovation (RRI) explicitly considers ethics and societal consequences as part of its core operations (Ribeiro et al. 2018; Smallman 2018). It has been gaining traction in Europe for several years now and has even been applied to the regulation of big tech firms (Peckham 2018). Even for researchers who do not directly engage with impact, RRI can capitalize on serendipity: if potential impacts are discovered during the research process, the researchers can pass them off for others to pursue without feeling compelled to do so themselves (Holbrook 2019). RRI brings social impact to the fore of research.

Practices of public involvement in S\&T policy go back decades. Mottur (1970) argued for citizen participation in technology assessment. The US 
Office of Technology Assessment, founded soon afterwards, took this advice to heart. It routinely established a public advisory council for every one of its major assessments until it was shut down in 1995 (Chalk 1974; Redelfs and Stanke 1987). In the 1990s, breast cancer patients collaborated with the DoD to explicitly select and guide different research and treatment options (Sarewitz 2016). In Europe, the Danish Board of Technology organized "consensus conferences." These were groups of ten to fifteen citizens who questioned S\&T experts around politically charged technologies and wrote reports summarizing their consensus (Joss and Durant 1995). Other options for public participation include public hearings, negotiated rulemaking, public opinion surveys and focus groups (Rowe and Frewer 2000). It is also important that any public participation be structured so citizens clearly understand the choices at hand, the pros and cons of each one, and how benefits to one stakeholder may disadvantage another (Gregory et al. 2005). Nightingale and Scott (2007) recommend that "research proposals should show a clear and rigorous understanding of the diverse actors involved in the field of enquiry and their particular research needs." A set of well-trained participants with diverse perspectives produce better solutions to difficult problems than specialized experts working alone, on average (Page 2007). Even without direct public participation, cost-benefit analysis can be improved to account for equity (Hahn 2021). This ample evidence thoroughly justifies integrating public input into research funding decisions.
Participatory technology assessment (Weller et al. 2020 ) is very similar to this paper's proposal. It can serve as a model when considering implementation details. Maintaining such a system in every phase of the S\&T R\&D process allows those in need to advocate for solutions that help them, and also fulfills their rights as taxpaying citizens who help fund the research (Sclove 2010). However, this requires adopting the view directly opposing Bush's: decisions in science are not to be made solely by scientists. Science benefits everyone and must therefore be treated like the multistakeholder endeavor that it truly is.

\section{Conclusion}

The US has enjoyed several decades of technology development and growth, but it faces as many challenges as ever in issues like environmental quality, social justice, economic disparities and infrastructure decay. It is long past time to fully attune our science enterprises to these causes. We cannot simply frame the success of our S\&T system around financial goals like number of jobs or startups generated, national competitiveness or gross domestic product. Nor can we continue to produce technologies that largely benefit the already comfortable and ethically claim that we are truly innovating (Bozeman 2020). Amidst calls for a "civilian DARPA" (Clauser and Skaluba 2020) and attempts to align NSF with social issues (Ambrose 2021), we in the science community are due for a reckoning. We must bring everyone together within the same collective impact framework, regardless of how each individual chooses to contribute. This will help ensure we have an innovation system that innovates for all, not just some.

\section{References}

Alakent, Ekin, M. Sinan Goktan, and Theodore A. Khoury. 2020. "Is Venture Capital Socially Responsible? Exploring the Imprinting Effect of VC Funding on CSR Practices." Journal of Business Venturing 35 (3): 106005.

https://doi.org/10.1016/j.jbusvent.2020.106005.

Ambrose, Mitch. 2021. "Science Committee Makes Counterproposal to Endless Frontier Act." American Institute of Physics, March 26, 2021. https://www.aip.org/fyi/2021/sciencecommittee-makes-counterproposal-endlessfrontier-act.
Bozeman, Barry. 2020. "Public Value Science." Issues in Science and Technology 36 (4). https://issues.org/public-value-scienceinnovation-equity-bozeman.

Bozeman, Barry, and Craig Boardman. 2009. "Broad Impacts and Narrow Perspectives: Passing the Buck on Science and Social Impacts." Social Epistemology 23 (3-4): 183-98. https://doi.org/10.1080/02691720903364019.

Bush, Vannevar. 1945. "Science, The Endless Frontier." Transactions of the Kansas Academy of Science 48 (3): 231. https://doi.org/10.2307/3625196. 
Chalk, Rosemary. 1974. "Public Participation and Technology Assessment: A Survey of the Legislative History of the Office of Technology Assessment." Congressional Research Service. https://ota.fas.org/reports/0086.pdf.

Clauser, Michael, and Sarah Skaluba. 2020. "It's Time the Civilian Sector Had Its Own DARPA." Access Partnership (blog). July 7, 2020. https://www.accesspartnership.com/its-timethe-civilian-sector-had-its-own-darpa.

Dance, Amber. 2013. "Impact: Pack a Punch." Nature 502 (7471): 397-98. https://doi.org/10.1038/nj7471-397a.

Godin, Benoît, and Christian Doré. 2005. "Measuring the Impacts of Science: Beyond the Economic Dimension." http://www.csiic.ca/PDF/Godin Dore Impacts.p df.

Green, Richard J., and Wil Lepkowski. 2006. "A Forgotten Model for Purposeful Science." Issues in Science and Technology 22 (2). https://issues.org/green-2.

Gregory, Robin, Baruch Fischhoff, and Tim McDaniels. 2005. "Acceptable Input: Using Decision Analysis to Guide Public Policy Deliberations." Decision Analysis 2 (1): 4-16. https://doi.org/10.1287/deca.1050.0035.

Hahn, Robert W. 2021. "Equity in Cost-Benefit Analysis." Science 372 (6541): 439-439. https://doi.org/10.1126/science.abg9534.

Heleta, Savo. 2017. "Academics Can Change the World - If They Stop Talking Only to Their Peers." The Conversation, March 31, 2017. https://theconversation.com/academics-canchange-the-world-if-they-stop-talking-only-totheir-peers-55713.

Holbrook, J. Britt. 2017. "The Future of the Impact Agenda Depends on the Revaluation of Academic Freedom." Palgrave Communications 3 (1): 39. https://doi.org/10.1057/s41599-017-0041-0.

Holbrook, J. Britt. 2019. “Designing Responsible Research and Innovation to Encourage Serendipity Could Enhance the Broader Societal Impacts of Research." Journal of Responsible Innovation 6 (1): 84-90. https://doi.org/10.1080/23299460.2017.14103 26.

Holbrook, J. Britt, and Robert Frodeman. 2011. “Peer Review and the Ex Ante Assessment of Societal Impacts." Research Evaluation 20 (3): 239-46. https://doi.org/10.3152/095820211X12941371 $\underline{876788 .}$
Ioannidis, John P. A., Kevin W. Boyack, Henry Small, Aaron A. Sorensen, and Richard Klavans. 2014. "Bibliometrics: Is Your Most Cited Work Your Best?" Nature 514 (7524): 561-62. https://doi.org/10.1038/514561a.

Joss, Simon, and John Durant, eds. 1995. Public Participation in Science: The Role of Consensus Conferences in Europe. London.

Kania, John, and Mark Kramer. 2011. "Collective Impact." Stanford Social Innovation Review, 2011. https://ssir.org/articles/entry/collective impact.

Kevles, Daniel J. 1977. "The National Science Foundation and the Debate over Postwar Research Policy, 1942-1945: A Political Interpretation of Science, The Endless Frontier." Isis 68 (1): 5-26. https://doi.org/10.1086/351711.

Langfeldt, Liv, and Lisa Scordato. 2015. "Assessing the Broader Impacts of Research: A Review of Methods and Practices." Nordic Institute for Studies in Innovation, Research and Education. https://www.nifu.no/en/publications/1239706.

Leeming, Jack. 2018. "How Researchers Are Ensuring That Their Work Has an Impact." Nature 556 (7699): 139-41. https://doi.org/10.1038/d41586-018-03925-8.

Loise, Vicki, and Ashley J. Stevens. 2010. "The Bayh-Dole Act Turns 30." Science Translational Medicine 2 (52): 52cm27-52 cm27. https://doi.org/10.1126/scitranslmed.3001481.

Lok, Corie. 2010. "Science for the Masses." Nature 465 (7297): 416-18. https://doi.org/10.1038/465416a.

Lopez, German. 2021. "How Congress Wrecked Its Own Science Bill, Explained in 600 Words." Vox, June 4, 2021.

https://www.vox.com/2021/6/4/22518923/en dless-frontier-act-innovation-competition-actchina-congress.

MacFadden, Bruce J. 2019. Broader Impacts of Science on Society. 1st ed. Cambridge University Press. https://doi.org/10.1017/9781108377577.

Mazuzan, George T. 1994. "The National Science Foundation: A Brief History." July 15, 1994. https://www.nsf.gov/about/history/nsf50/nsf8 816.jsp.

McCarthy, Ian P., Bruno S. Silvestre, Andrew von Nordenflycht, and Shiri M. Breznitz. 2018. "A Typology of University Research Park Strategies: What Parks Do and Why It Matters." Journal of Engineering and Technology Management 47 (January): 110-22. https://doi.org/10.1016/j.jengtecman.2018.01.0 $\underline{04}$. 
McKinnon, John D. 2021. "House Passes Bipartisan Bill to Boost Scientific Competitiveness, Following Senate." Wall Street Journal, June 29, 2021, sec. Politics. https://www.wsj.com/articles/housepasses-bipartisan-bill-to-boost-scientificcompetitiveness-following-senate-11624941848.

Mottur, Ellis R. 1970. “Technology Assessment and Citizen Action." 10. Program of Policy Studies in Science and Technology. Washington, D.C.: George Washington University. https://ota.fas.org/reports/0645.pdf.

Myers, Kyle. 2020. "The Elasticity of Science." American Economic Journal: Applied Economics 12 (4): 10334.

https://doi.org/10.1257/app.20180518.

National Aeronautics and Space Administration. n.d. "About Spinoff." About Spinoff. https://spinoff.nasa.gov.

National Science Foundation. 2015. "Perspectives on Broader Impacts."

https://www.nsf.gov/od/oia/publications/Broad er Impacts.pdf.

National Science Foundation. n.d. "About the National Science Foundation - Who We Are." Accessed June 2, 2021. https://www.nsf.gov/about.

Nightingale, Paul, and Alister Scott. 2007. "Peer Review and the Relevance Gap: Ten Suggestions for Policy-Makers." Science and Public Policy 34 (8): 543-53. https://doi.org/10.3152/030234207X254396.

Page, Scott E. 2007. "Making the Difference: Applying a Logic of Diversity." Academy of Management Perspectives 21 (4): 6-20. https://doi.org/10.5465/amp.2007.27895335.

Peckham, James. 2018. "What Is Responsible Innovation, and Why Should Tech Giants Take It Seriously?" TechRadar, August 27, 2018. https://www.techradar.com/news/what-isresponsible-innovation-and-why-should-techgiants-take-it-seriously.

Pielke, Roger A. 2010. "In Retrospect: Science, The Endless Frontier." Nature 466 (7309): 922-23. https://doi.org/10.1038/466922a.

Pielke, Roger A., and Radford Byerly. 1998. "Beyond Basic and Applied." Physics Today 51 (2): 42-46. https://doi.org/10.1063/1.882141.

Prabhakar, Arati. 2020. "In the Realm of the Barely Feasible." Issues in Science and Technology 37 (1). https://issues.org/realm-of-the-barely-feasibleinnovation-darpa-prabhakar.
Redelfs, Manfred, and Michael Stanke. 1987. "Citizen Participation in Technology Assessment: Practice at the Congressional Office of Technology Assessment." Washington, D.C.: George Washington University. https://ota.fas.org/reports/0881.pdf.

Ribeiro, Barbara, Lars Bengtsson, Paul Benneworth, Susanne Bührer, Elena Castro-Martínez, Meiken Hansen, Katharina Jarmai, et al. 2018. "Introducing the Dilemma of Societal Alignment for Inclusive and Responsible Research and Innovation." Journal of Responsible Innovation 5 (3): 316-31. https://doi.org/10.1080/23299460.2018.14950 $\underline{33}$.

Rowe, Gene, and Lynn J. Frewer. 2000. "Public Participation Methods: A Framework for Evaluation." Science, Technology, \& Human Values 25 (1): 3-29.

https://doi.org/10.1177/016224390002500101.

Sarewitz, Daniel. 2011. "The Dubious Benefits of Broader Impact." Nature 475 (7355): 141-141. https://doi.org/10.1038/475141a.

Sarewitz, Daniel. 2016. "Saving Science." The New Atlantis 49.

https://www.thenewatlantis.com/publications/s aving-science.

Sarewitz, Daniel. 2021. "Inside Science Politics." Issues in Science and Technology 37 (3). https://issues.org/inside-science-politicseditors-journal-sarewitz.

Schikowitz, Andrea. 2020. "Creating Relevant Knowledge in Transdisciplinary Research Projects - Coping with Inherent Tensions." Journal of Responsible Innovation 7 (2): 217-37. https://doi.org/10.1080/23299460.2019.16531 $\underline{54 .}$

Schillo, R. Sandra, and Ryan M. Robinson. 2017. "Inclusive Innovation in Developed Countries: The Who, What, Why, and How." Technology Innovation Management Review 7 (7): 34-46. https://doi.org/10.22215/timreview/1089.

Sclove, Richard. 2010. "Reinventing Technology Assessment: A 21st Century Model,." Woodrow Wilson International Center for Scholars. https://www.wilsoncenter.org/article/reinventi ng-technology-assessment-for-the-21st-century.

Shneiderman, Benjamin. 2013. "Toward an Ecological Model of Research and Development." The Atlantic. April 23, 2013.

https://www.theatlantic.com/technology/archiv e/2013/04/toward-an-ecological-model-ofresearch-and-development/275187. 
Smallman, Melanie. 2018. "Citizen Science and Responsible Research and Innovation." In Citzen Science: Innovation in Open Science, Society and Policy, edited by Susanne Hecker, Muki Haklay, Anne Bowser, Zen Makuch, Johannes Vogel, and Aletta Bonn, 241-53. UCL Press. https://doi.org/10.14324/111.9781787352339.

Smith, Gary N., and Jeffrey Funk. 2021. "Why We Need to Stop Relying On Patents to Measure Innovation." ProMarket (blog). March 19, 2021. https://promarket.org/2021/03/19/patentsbad-measure-innovation-new-metric.

Stevens, Ashley J. 2004. "The Enactment of Bayh-Dole." The Journal of Technology Transfer 29 (1): 93-99. https://doi.org/10.1023/B:JOTT.0000011183.40 867.52.

Stokes, Donald E. 1997. Pasteur's Quadrant: Basic Science and Technological Innovation. Washington, D.C: Brookings Institution Press.

Trager, Rebecca. 2015. "Battle over Science Funding Gets Fiercer in U.S. Congress.” Scientific American, March 23, 2015.

https://www.scientificamerican.com/article/batt le-over-science-funding-gets-fiercer-in-u-scongress.
Van Norman, Gail A., and Roï Eisenkot. 2017. "Technology Transfer: From the Research Bench to Commercialization." JACC: Basic to Translational Science 2 (2): 197-208. https://doi.org/10.1016/j.jacbts.2017.03.004.

Wang, Jessica. 1995. "Liberals, the Progressive Left, and the Political Economy of Postwar American Science: The National Science Foundation Debate Revisited." Historical Studies in the Physical and Biological Sciences 26 (1): 139-66. https://doi.org/10.2307/27757758.

Weller, Nicholas, Michelle Sullivan Govani, and Mahmud Farooque. 2020. "Supporting Federal Decision Making through Participatory Technology Assessment." Day One Project. https://www.dayoneproject.org/post/supportin g-federal-decision-making-throughparticipatory-technology-assessment.

Wilson, John Todd. 1983. Academic Science, Higher Education, and the Federal Government, 19501983: John T. Wilson. Chicago: University of Chicago Press.

Jeremy Pesner is a Ph.D. student in Engineering and Public Policy at Carnegie Mellon University, where he focuses on policy issues of information and communication technologies, telecommunications, technology innovation and futurism. He earned his BS in Computer Science at Dickinson College and his MA in Communication, Culture \& Technology from Georgetown University. He is a member of the Association for Computing Machinery, the Institute for Electrical and Electronic Engineers, the American Association for the Advancement of Science and the National Science Policy Network. He has helped organize the STGlobal Conference on Science and Society and has presented at venues including the World Future Society, Hackers on Planet Earth, TEDx Herndon and ComSciCon.

\section{Acknowledgments}

I am deeply indebted to Professor Zachary Taylor for his support and guidance in this idea's formation. I am very grateful for his patience as I struggled through the initial process of refining and organizing my ideas, and with his help soon turned my unrefined arguments into concrete narratives. Professor Phillip Shapira also contributed a good deal of insight and direction in this paper's early stages. I also wish to extend my gratitude to Sky Gross, Eileen Oni, Avery Sen, several of Carnegie Mellon's communication support tutors and my JSPG editors Jason Albert and Benjamin Wolfson for their helpful comments on my paper drafts.

\section{Disclaimer}

I declare no conflicts of interest. 